\title{
Takayasu Arteritis: A Case Presenting With Neurological Symptoms and Proteinuria
}

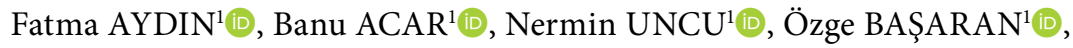

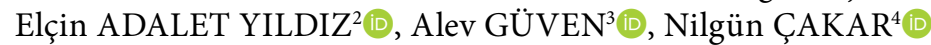

\begin{abstract}
${ }^{1}$ Department of Pediatric Rheumatology, Ankara Child Health, Hematology Oncology Training and Research Hospital, Ankara, Turkey ${ }^{2}$ Department of Pediatric Radiology, Ankara Child Health, Hematology Oncology Training and Research Hospital, Ankara, Turkey ${ }^{3}$ Department of Pediatric Neurology, Ankara Child Health, Hematology Oncology Training and Research Hospital, Ankara, Turkey ${ }^{4}$ Department of Pediatric Rheumatology and Nephrology, Ankara University School of Medicine, Ankara, Turkey
\end{abstract}

\begin{abstract}
In this article, we present an 18-year-old female patient who was initially diagnosed as central nervous system vasculitis and focal segmental glomerulosclerosis but later diagnosed as Takayasu arteritis.

Keywords: Glomerulonephritis; neurologic manifestations; proteinuria, stroke, Takayasu arteritis.
\end{abstract}

Takayasu arteritis (TA) is a rare, chronic, relapsing, granulomatous large vessel vasculitis affecting the aorta, its major branches, and pulmonary arteries. In general, the initial manifestations of TA include constitutional symptoms, limb claudication, decreased arterial pulse, heart murmurs, arterial hypertension and blood pressure asymmetry. Lack of specific features, particularly in childhood, causes delayed diagnosis. ${ }^{1}$

In this article, we report a patient who was initially diagnosed as central nervous system vasculitis and focal segmental glomerulosclerosis (FSGS) and who turned out to have TA during follow-up.

\section{CASE REPORT}

A 14-year-old female patient referred to our clinic with headache and dizziness for two weeks and loss of consciousness for about 10 minutes. On admission, the blood pressure was $90 / 60 \mathrm{mmHg}$ and all peripheral pulses were palpable. Her body weight was above $97^{\text {th }}$ percentile for her age and body mass index was 33. The fundus examination and other organ systems were essentially normal. Laboratory studies revealed erythrocyte sedimentation rate (ESR) as $108 \mathrm{~mm} /$ hour and C-reactive protein (CRP) as $7.5 \mathrm{mg} / \mathrm{dL}(0-0.8)$, while other measurements were normal. Urinalysis revealed microscopic hematuria and proteinuria of

Received: January 12, 2019 Accepted: July 01, 2019 Published online: February 07, 2020

Correspondence: Fatma Aydın, MD. Ankara Çocuk Sağlığı, Hematoloji Onkoloji Eğitim ve Araştırma Hastanesi Pediatrik Romatoloji Kliniği, 06110 Altındağ, Ankara, Turkey. Tel: +90 $505-8883848$ e-mail: fatma4326@yahoo.com 

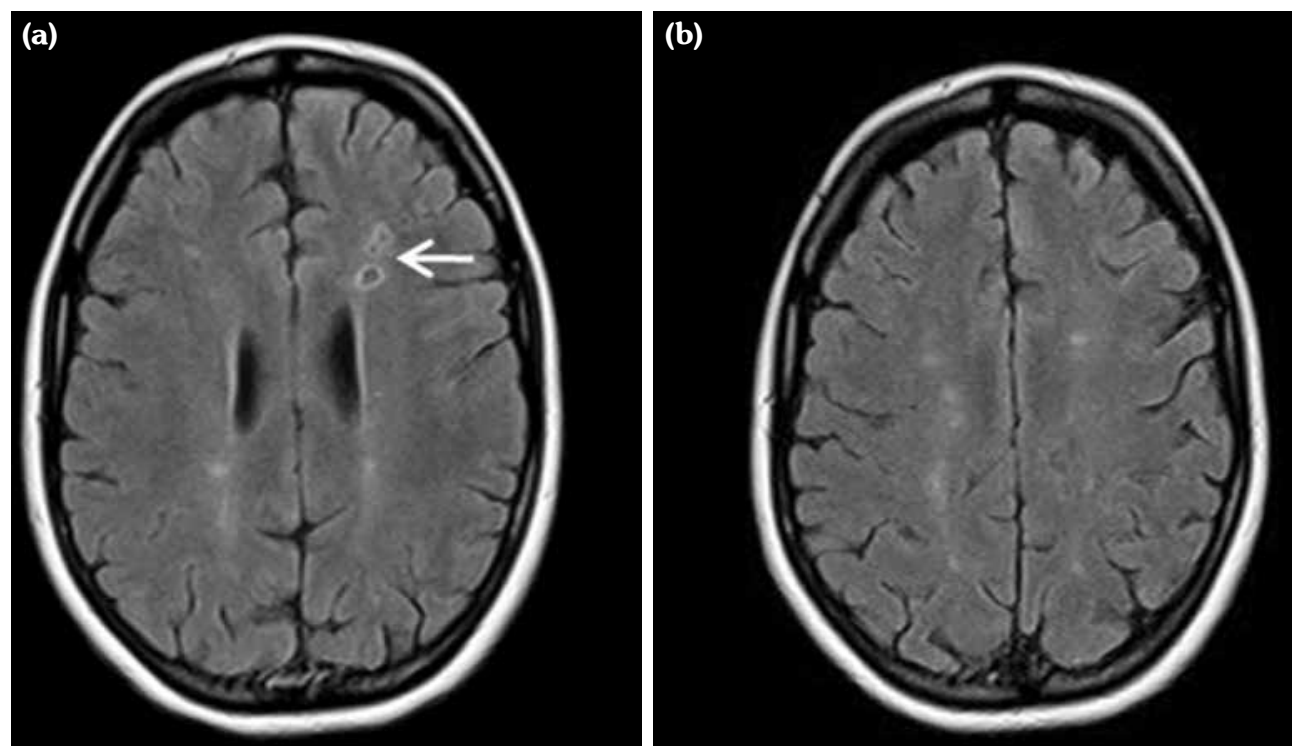

Figure 1. Fluid-attenuated inversion recovery imaging crossing ventricular (a) and centrum semiovale levels (b) revealed multiple millimetric hyperintense lesions at deep white matter. Left frontal periventricular white matter lesions demonstrated marginal gliotic hyperintensity.

$31.9 \mathrm{mg} / \mathrm{m}^{2} /$ hour in 24-hour urine collection. The cerebrospinal fluid examination showed no abnormalities. Cranial magnetic resonance imaging (MRI) showed multiple millimetric hyperintense deep white matter lesions on T2-weighted imaging (Figure 1). Intracranial and extracranial arteries were normal in magnetic resonance angiography (MRA). Renal biopsy findings were interpreted as FSGS (Figure 2). Patient was considered as cerebral vasculitis and incidental FSGS. Pulse methylprednisolone therapy for three consecutive days was initiated and continued with oral prednisolone. At four years of follow-up, proteinuria decreased to $5-15 \mathrm{mg} / \mathrm{m}^{2}$ /hour, and ESR and CRP were normal. Repeated brain MRI and MRA examinations showed no new lesions. Four years later, at the age of 18 , on a routine examination, both radial artery pulses were absent and the blood pressure could not be measured. Significant bruit was heard on the left carotid artery. Laboratory studies revealed

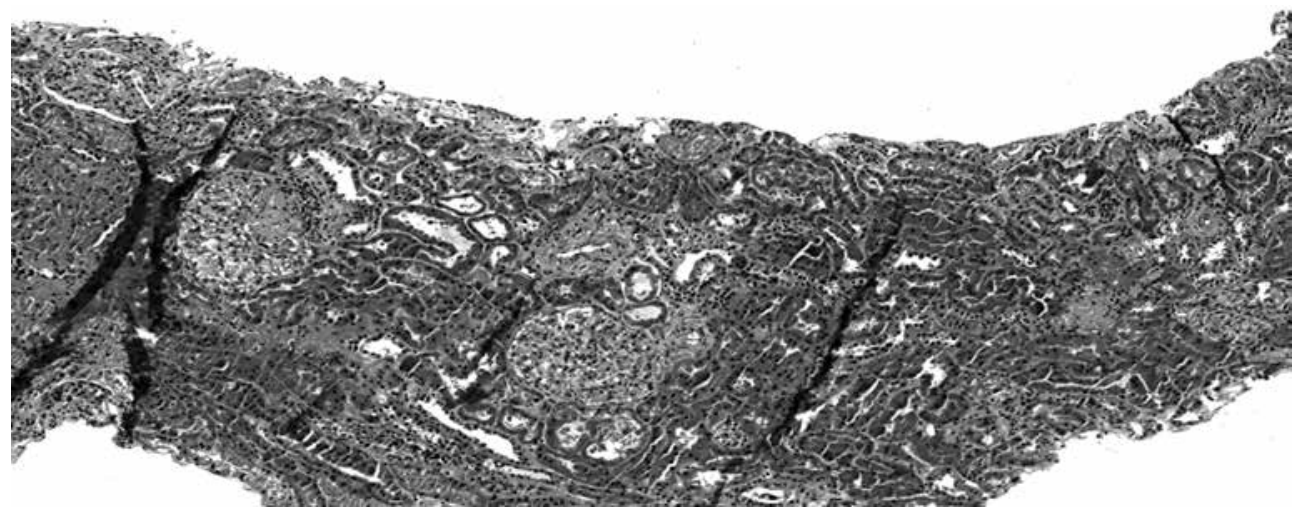

Figure 2. Eleven glomeruli with mild lobulation and mesangial hypercellularity. Three glomeruli had global sclerosis and four-five glomeruli had segmental sclerosis. Negative results were obtained for immunoglobulins $\mathrm{G}, \mathrm{M}$ and $\mathrm{A}$, complement factors 3 and 1q, fibrinogen, kappa, and lambda by immunofluorescence. 


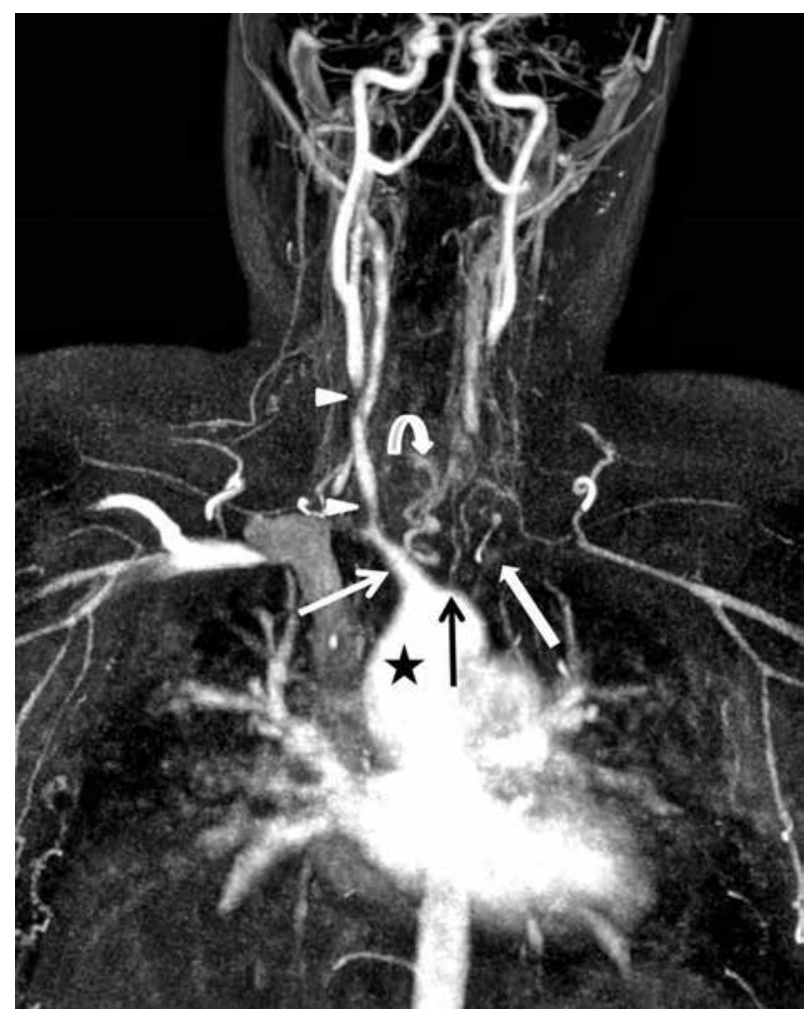

Figure 3. Diffuse wall thickening in arcus aorta (star) and brachiocephalic artery (white arrow). Left common carotid (black arrow) and proximal segment of left subclavian (thick arrow) arteries had preocclusive stenosis.

ESR as $43 \mathrm{~mm} /$ hour and CRP as $2.46 \mathrm{mg} / \mathrm{dL}$. Aortic MRA revealed diffuse wall thickening and contrast enhancement in the arcus aorta and its many main branches (Figure 3). Takayasu arteritis diagnosis was established according to the European League Against Rheumatism/ Paediatric Rheumatology International Trials Organisation/Paediatric Rheumatology European Society criteria. ${ }^{2}$ Methotrexate was begun, and daily prednisolone was continued. Four months after the diagnosis of TA, left-sided hemiparesis developed. Brain MRI demonstrated a wide cerebral infarct at the right anterior vascular territory (Figure 4). Brain and neck computed tomography angiography showed total occlusion of the right internal carotid artery. Vascular involvement of the right common carotid artery was progressed to preocclusive stenosis. Diameters of the right anterior and middle cerebral arteries were thin and fed by the posterior and anterior communicating arteries (Figure 5). Tocilizumab treatment was started at $8 \mathrm{mg} / \mathrm{kg}$ every four weeks. At followup with 2.5 years of tocilizumab treatment, the patient's clinical condition improved slightly, and no new symptoms developed. A written informed consent was obtained from the patient.

\section{DISCUSSION}

Neurological manifestations are common symptoms in TA patients in the chronic phase, but they are uncommon in the early stages of the disease. ${ }^{3,4}$ Small vessel involvement can be the first manifestation of the disease and seriously
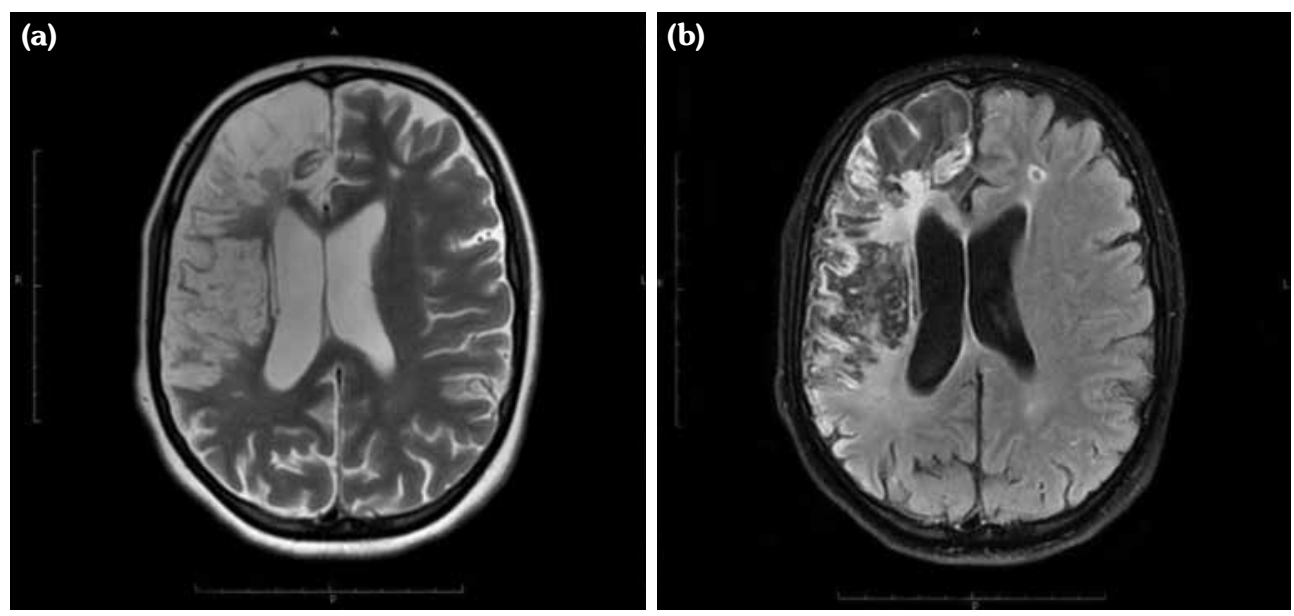

Figure 4. T2-weighted (a) and fluid-attenuated inversion recovery (b) images showed right frontoparietal cystic encephalomalacic parenchymal changes with hyperintense edematous areas consistent with subacute-chronic infarct. 


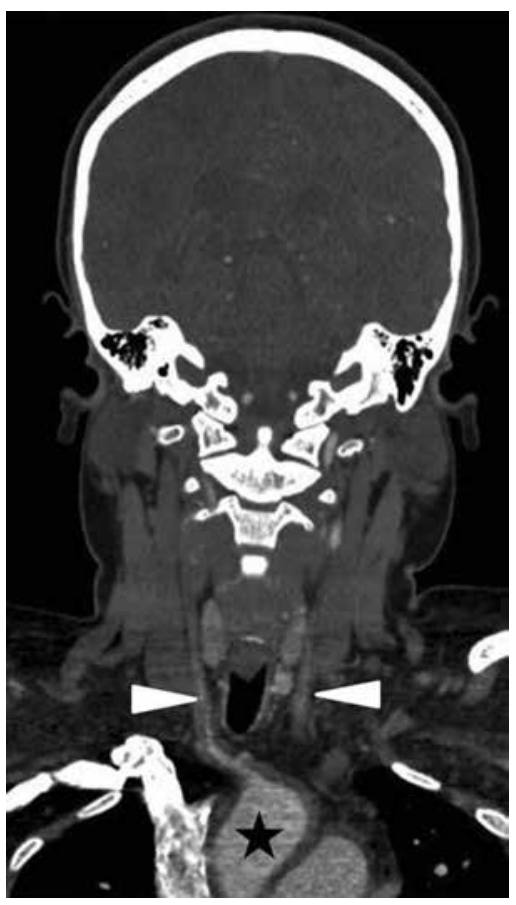

Figure 5. Coronal reformatted computed tomography angiography image showed diffuse wall thickening of arcus aorta (star), brachiocephalic artery and common carotid arteries. Both common carotid arteries had preocclusive stenosis (arrowheads).

impact the prognosis. ${ }^{5}$ Stroke, reported as the first symptom in 6-8\% of patients, may occur in $16-20 \%$ of patients during the course of the disease. ${ }^{3,4}$

Several causes of ischemic stroke in patients with TA have been described, including embolism from stenotic or occlusive lesions in the aortic arch and its main branches or cardiac diseases. ${ }^{6}$ In addition, intracranial stenosis have been observed as a consequence of vasculitic involvement or a prior embolization into the vessel. In our patient, based on the MRI scan, this cerebral accident seemed to be a vascular occlusion.

Renovascular hypertension is the most common renal manifestation of TA; however, proteinuria and nephrotic syndrome are both very rare and usually caused by factors other than FSGS. Four years before the diagnosis of TA, our patient was diagnosed as cerebral vasculitis. In the same period, renal biopsy performed due to proteinuria was reported as
FSGS. Cerebral vasculitis and TA in our patient may be coincidental with FSGS but it was supposed that immune complex deposition and vascular lesions caused glomerular ischemia in TA. ${ }^{7}$ Kuroda et al. ${ }^{8}$ reported a 50 -year-old female patient with TA who developed proteinuria and renal dysfunction with glomerulopathy mimicking membranoproliferative glomerulonephritis. They argue that increased vascular endothelial growth factor and interleukin (IL)-6 levels may cause renal disease.

Microvascular involvement might lead to glomerular ischemia and obesity might be an additional factor for developing FSGS in our patient. FSGS is a pattern of histologic injury rather than a disease. In obese patients, elevated plasma levels of leptin through upregulation of transforming growth factor beta 1 may also predispose to glomerulosclerosis. ${ }^{9}$

The clinical manifestations of TA can be very insidious in childhood and the diagnosis is often delayed. Therefore, the time between symptoms and diagnosis can last up to 2-11 years. Disease may be more resistant to treatment than adults. ${ }^{1,10}$

\section{Corticosteroids remain the mainstay} of treatment in TA and conventional immunosuppressive drugs have been used together with steroids while biologics have also been tried. ${ }^{11}$ It was reported that $88 \%$ of patients were inadequately controlled with conventional immunosuppressive therapy and overall response to biological-targeted drugs (tumor necrosis factor-alpha antagonists or tocilizumab) at 6 and 12 months was $75 \%$ and $83 \%$, respectively. ${ }^{12}$

Serum levels of IL- 6 have also been shown to correlate with disease activity. ${ }^{13}$ Tocilizumab, a humanized anti-IL-6 receptor inhibitory monoclonal antibody, is effective in inducing remission for patients with refractory TA. ${ }^{14}$

When our patient was diagnosed with TA, there was no evidence of newly developing cerebral vasculitis and organ involvement other than the aortic arch and main branches. Therefore, treatment was started with steroid and methotrexate. Tocilizumab was added to the treatment when stroke developed and vascular involvement worsened. While receiving this treatment, the clinical condition of our patient 
was partially improved, the acute phase reactants returned to normal at the sixth month and remained stable for two-and-a-half years.

Takayasu arteritis is a relatively rare disease and vascular changes may progress under the treatment with steroid and immunosupressive drugs. Thus, tocilizumab therapy may be effective in patients with refractory TA.

\section{Declaration of conflicting interests}

The authors declared no conflicts of interest with respect to the authorship and/or publication of this article.

\section{Funding}

The authors received no financial support for the research and/or authorship of this article.

\section{REFERENCES}

1. Lupi-Herrera E, Sánchez-Torres G, Marcushamer J, Mispireta J, Horwitz S, Vela JE. Takayasu's arteritis. Clinical study of 107 cases. Am Heart J 1977;93:94-103.

2. Ozen S, Pistorio A, Iusan SM, Bakkaloglu A, Herlin T, Brik R,et al. EULAR/PRINTO/PRES criteria for Henoch-Schönlein purpura, childhood polyarteritis nodosa, childhood Wegener granulomatosis and childhood Takayasu arteritis: Ankara 2008. Part II: Final classification criteria. Ann Rheum Dis 2010;69:798-806.

3. Arnaud L, Haroche J, Limal N, Toledano D, Gambotti L, Costedoat Chalumeau N, et al. Takayasu arteritis in France: a single-center retrospective study of 82 cases comparing white, North African, and black patients. Medicine (Baltimore) 2010;89:1-17.

4. Sato EI, Hatta FS, Levy-Neto M, Fernandes S. Demographic, clinical, and angiographic data of patients with Takayasu arteritis in Brazil. Int $\mathrm{J}$ Cardiol 1998;66:67-70.

5. Noel N, Butel N, Le Hoang P, Koskas F, CostedoatChalumeau N, Wechsler B, et al. Small vessel involvement in Takayasu's arteritis. Autoimmun Rev 2013;12:355-62.

6. de Paula LE, Alverne AR, Shinjo SK. Clinical and vascular features of Takayasu arteritis at the time of ischemic stroke. Acta Reumatol Port 2013;38:248-51.

7. Yoshimura M, Kida $H$, Saito $Y$, Yokoyama $H$, Tomosugi N, Abe T, et al. Peculiar glomerular lesions in Takayasu's arteritis. Clin Nephrol 1985;24:120-7.

8. Kuroda T, Ueno M, Sato H, Murakami S, Sakatsume $\mathrm{M}$, Nishi S, et al. A case of Takayasu arteritis complicated with glomerulonephropathy mimicking membranoproliferative glomerulonephritis: a case report and review of the literature. Rheumatol Int 2006;27:103-7.

9. Bose B, Cattran D. Glomerular diseases: FSGS. Clin J Am Soc Nephrol 2014;9:626-32.

10. Sahin S, Hopurcuoglu D, Bektas S, Belhan E, Adrovic A, Barut K, et al. Childhood-onset Takayasu arteritis: A 15-year experience from a tertiary referral center. Int J Rheum Dis 2019;22:132-9.

11. Johnston SL, Lock RJ, Gompels MM. Takayasu arteritis: a review. J Clin Pathol 2002;55:481-6.

12. Mekinian A, Comarmond C, Resche-Rigon M, Mirault T, Kahn JE, Lambert M, et al. Efficacy of Biological-Targeted Treatments in Takayasu Arteritis: Multicenter, Retrospective Study of 49 Patients. Circulation 2015;132:1693-700.

13. Park MC, Lee SW, Park YB, Lee SK. Serum cytokine profiles and their correlations with disease activity in Takayasu's arteritis. Rheumatology (Oxford) 2006;45:545-8.

14. Nakaoka $\mathrm{Y}$, Isobe $\mathrm{M}$, Takei $\mathrm{S}$, Tanaka $\mathrm{Y}$, Ishii $\mathrm{T}$, Yokota S, et al. Efficacy and safety of tocilizumab in patients with refractory Takayasu arteritis: results from a randomised, double-blind, placebo-controlled, phase 3 trial in Japan (the TAKT study). Ann Rheum Dis 2018;77:348-54. 